\title{
A MULHER NA CANÇÃO DE CHICO BUARQUE: da doméstica a independente
}

Taciana Ribeiro Rios de ABREU ${ }^{1}$

Luciano Marcos Dias CAVALCANTI ${ }^{2}$

\begin{abstract}
${ }^{1}$ Graduanda do Curso de Psicologia da Universidade Vale do Rio Verde - UNINCOR - TC, tacianaribeirorios@ymail.com.

${ }^{2}$ Doutor em Teoria e História Literária pelo IEL/UNICAMP, Professor do Programa de Mestrado em Letras: Linguagem, Cultura e Discurso da Universidade Vale do Rio Verde (UNINCOR), prof.luciano.cavalcanti@unincor.edu.br
\end{abstract}

Recebido em: 17/08/2016- Aprovado em: 20/11/2017 - Disponibilizado em: 30/12/2017

\begin{abstract}
RESUMO
Este artigo pretende examinar a representação da mulher em algumas letras de Chico Buarque de Hollanda, um dos maiores nomes de nossa música popular. Para tanto, refletiremos sobre a construção de suas personagens femininas inseridas em contexto sociocultural patriarcal de nossa sociedade, que deu ao homem poder no espaço privado, como chefe da família, e no público. Nesse sentido, muitas das canções de Chico, que destacam as mulheres, revelam que estas, subjugadas pela dominação masculina, não expressam sua voz e suas escolhas, sonhos e desejos, como vemos nas canções como "Cotidiano", "Folhetim" e "Mulheres de Atenas". Em paralelo a essa representação do feminino, Chico constrói também personagens femininas que assumem o controle de suas vidas, que fazem suas escolhas e rompem com a cultura patriarcal dominante, como ocorre nas canções "Mil perdões", "Madalena", Teresinha".
\end{abstract}

Palavras Chave: Chico Buarque, mulher, dominação masculina, escolhas.

\begin{abstract}
This article intends to examine the representation of women in the lyrics of Chico Buarque de Hollanda, one of the greatest names of our popular music. Therefore, we'll discuss about the construction of his female characters inside the patriarchal culture of our society, that empowered men in private spaces, as the head of the family, and in public. In this sense, a lot of Chico's songs, that highlight women, reveal that those, subjugated by the male domination, don't express their voices and their choices, wishes and dreams, as we see in the songs "Cotidiano", "Folhetim" and "Mulheres de Atenas". Parallel to this representation of women, Chico also builds female characters that take control over their own lives, that make their own choices and break with the dominant patriarchal culture, as it happens in the songs: "Mil perdões", "Madalena", “Teresinha".
\end{abstract}

Keywords: Chico Buarque, Woman, Chico Buarque, male domination, choices.

\section{Introdução}

Partindo de algumas reflexões sobre as canções de Chico Buarque de Hollanda, temos como proposta analisar o modo pelo qual o compositor representa determinados tipos de mulheres em suas canções: a mulher submissa aos preceitos machistas e a mulher que rompe os grilhões do controle masculino. Nesse sentido, muitas das canções de Chico
Buarque, que destacam as mulheres, revelam que estas, subjugadas pela dominação masculina, não expressam sua voz em suas escolhas, sonhos e desejos. Em paralelo a essa representação do feminino, Chico Buarque também constrói personagens femininas que assumem o controle de sua vida, que fazem suas escolhas e rompem com a cultura patriarcal dominante. 
De acordo com Adélia Bezerra de Menezes, em seu livro Figuras do feminino na canção de Chico Buarque,

É inegável que a canção de
Chico privilegia a fala da
mulher, assim como na
galeria das suas
personagens sobressai o
marginal como
protagonista, pondo a nu,
desta maneira, a
negatividade da sociedade.
[... O seu discurso dá voz
aqueles que em geral não
têm voz. Assim,
encontraremos o tema das
mulheres vinculado ao
tema da marginalidade
social. (MENEZES, 2001,
p. 41).

Para empreendermos nosso propósito será necessário pensarmos de maneira crítica sobre a estrutura patriarcal de nossa sociedade, que deu ao homem poder no espaço privado, como chefe da família, e no público, lugar onde ele sempre se movimentou de maneira soberana. $\mathrm{O}$ patriarcado é um modelo estrutural que por um longo tempo se manteve fortalecido em nossa sociedade por valores machistas, em que a dominação masculina se revela principalmente no tratamento desigual imposto a mulher em relação ao homem. Percebemos que nas canções de Chico Buarque, a partir de tais condições socioculturais, a mulher sempre ocupou uma posição de submissão. Neste sentido, é perceptível na obra do compositor a representação do feminino oprimido sem voz e subjugado pela dominação masculina, ideologia que impede a mulher de se expressar, de ter escolhas, realizar seus sonhos e desejos, como podemos notar nas canções como "Cotidiano" "Folhetim" e "Mulheres de Atenas".

$\mathrm{Na}$ canção "Cotidiano", Chico Buarque retrata a rotina de um casal em que a mulher é representada como a organizadora do lar. Todos os dias de maneira mecânica, programada, ela acorda o marido para o trabalho e, à noite, o espera no portão, reforçando o eu lírico que "Todo dia ela faz tudo sempre igual". A expressão "Todo dia" é repetida cinco vezes, mostrando essa condição mecânica dos afazeres diários, em um movimento de repetição compulsiva e insuportável, somada à responsabilidade de cumprir o trabalho doméstico. Aqui, a lógica estabelecida é de um mundo cíclico, pois a última estrofe se conecta à primeira, de modo que inicia "todo dia" e encerra "toda noite" fazendo tudo sempre igual. Esta mulher pode ser comparada ao operário, que reproduz cotidianamente sua rotina de trabalho: acordando pontualmente no mesmo horário e reproduzindo dia a dia as mesmas atribuições de maneira repetida. Esta relação se torna monótona e exaustiva, não sendo permitida a ambos, a mulher e seu companheiro, a ampliação de seus modos de vida.

Como explica Adélia Bezerra de Menezes: 
Numa inversão dos estereótipos habituais quanto à passividade, a mulher aqui é ativa [...] ativíssima por sinal: num espaço de poucos versos, ela faz, sacode, sorri, diz, diz mais ainda, jura, aperta, mas sobretudo beija: beija com a boca de hortelã, beija com a boca de café, beija com a boca de paixão, e beija, ou melhor, morde, com a boca de pavor, o beijo vira mordida. Estabelece-se uma inversão de sinais, em que os gestos do afeto se transmudam os signos da prisão. (MENEZES, 2001, p. 49)

Chico Buarque (de maneira sutil) critica essa falta de dinamicidade da vida, em que a mulher é ausente de criatividade, repete cotidianamente suas tarefas domésticas no lar, sufoca seus desejos e aplaca sua potência de viver, sem espaço para desejar, nem independência. Esta afirmação é endossada pela análise desta canção por Adélia Bezerra ao dizer que esta mulher é ativíssima, mas é previsível e age como um operário que cumpre todo o seu ritual. Ela é ausente de espontaneidade criativa. Condição esta desempenhada pela figura feminina nos tempos passados e infelizmente por uma parcela significativa nos tempos atuais, em que se sujeita consciente e inconscientemente a viver dessa maneira, em que tanto a mulher quanto o homem se encontram aprisionados em um cotidiano massacrante e rotineiro do lar, impossibilitando-os desenvolver novas possibilidades de vida.

Assim, nesta canção, fica claro o motivo da existência dessa mulher, viver para seu marido, manter a ordem, ficando aprisionada aos seus afazeres do lar e o homem aprisionado neste sistema disfuncional.

A figura feminina também é representada nas canções de Chico como um objeto sexual quando foge às padronizações culturalmente estipuladas, se associando a estereótipos machistas em que nossas raízes estão fincadas. Podemos citar, por exemplo, adjetivos que qualificam esta mulher: transgressora, vulgar, mentirosa, agressiva, infiel, que vem para desestruturar o homem, ou seja, aquela que vem para destruir o sistema patriarcal pré-estabelecido.

Conforme a explicação de Cilene Pereira, em seu artigo “"Rita', de Chico Buarque (e outras histórias femininas de devastação)",

[...] se a mulher não se coloca do lado sentimental, evidenciando fragilidade emocional e destreza com os papéis domésticos, dos quais o ser mãe e esposa são fundamentais em sua trajetória existencial, ela pode se revelar "piranha", isto é, uma desajustada da norma. (PEREIRA, 2017, p. 3)

Percebemos essas classificações estereotipadas na canção "Folhetim", na qual o eu lírico apresenta a realidade de uma mulher que sai de todos os padrões 
estabelecidos para um lugar desconhecido, com a conduta de desorganizar o lar, sem exclusividade em suas relações, a qual preconceituosamente é rotulada pela sociedade como imoral, enganosa, sem pudor, transgressora, "prostituta", como podemos notar em sua primeira estrofe: "Se acaso me quiseres/Sou dessas mulheres/Que só dizem sim/Por uma coisa à toa/Uma noitada boa/Um cinema, um botequim".

Esta afirmação é confirmada pela análise desta canção por Adélia Bezerra ao dizer que

É com Folhetim que se evidencia a relação de poder que está à base da prostituição, mas, aqui, significativamente, com seu sinal invertido: ao fim, é a mulher, uma dessas "que só dizem sim", que "aceitam uma prenda", é ela que vai manipular o homem. (MENEZES, 2001, p. 77)

Em "As Mulheres de Atenas", Chico Buarque nos apresenta a condição de submissão e espera em que as mulheres donas do lar se sujeitavam, verificável pelas variadas violências em que são submetidas: simbólicas, físicas e psíquicas. Assim, nesta canção, essas mulheres vivem e secam até a morte pelos seus maridos. Essa canção nos possibilita vislumbrar como a cultura patriarcal fez das mulheres um alicerce para os homens como uma âncora que não movimenta, sem vida, fixa em um mesmo lugar, como se pode ver na oitava estrofe da canção: "Elas não têm gosto ou vontade/Nem defeito, nem qualidade/Têm medo apenas/Não tem sonhos, só tem presságios/O seu homem, mares, naufrágios/Lindas sirenas, morenas". Adélia Bezerra questiona os adjetivos remetidos às mulheres de Atenas, “Quais são as ‘qualidades’ e características femininas, ironicamente colocadas como 'exemplos' para as mulheres"? (MENEZES, 2001, p. 153)

Mulheres que zelavam pelos homens e pelas regras. Não se expunham para a sociedade, escondiam-se e guardavam para seus maridos. De fato, essas mulheres sofriam pelos seus maridos, sofriam quando estavam longe e quando estavam próximas a eles, teciam longos trabalhos por anos a espera se guardando para os maridos. Através dessa canção Chico mostra a condição em que a mulher é sujeitada e, ao revelar esta situação, enuncia o caminho para a sua libertação.

Estas canções criadas por Chico Buarque nos possibilitam compreender que por grandes períodos no decorrer da história as mulheres não tiveram escolhas. Viveram oprimidas e sujeitas aos papéis estipulados pela cultura patriarcal.

Segundo Manoel Tosta Berlinck, em "Sossega leão! Algumas considerações sobre o samba como forma de cultura popular", é possível notar na música popular brasileira três tipos de mulheres: "a doméstica", "a 
piranha”, e “a onírica”. (BERLINCK, 1976, p. 102).

Berlinck descreve cada uma destas três imagens femininas:

\begin{abstract}
A mulher ideal é a doméstica, ao mesmo tempo submissa e passiva; que aceita com resignação aquilo que o homem lhe oferece e acha bonito tudo o que o homem lhe dá. (BERLINCK, 1976, p. 103)
\end{abstract}

Em seguida, ele descreve a "piranha":

$$
\begin{aligned}
& \text { A principal característica } \\
& \text { da 'mulher piranha' é a } \\
& \text { traição; trata-se de criatura } \\
& \text { 'sem moral, sem } \\
& \text { compostura, sem coração, } \\
& \text { sem pudor' porque } \\
& \text { invariavelmente trai o } \\
& \text { companheiro. } \\
& \text { (BERLINCK, 1976, p. } \\
& \text { 107) }
\end{aligned}
$$

E, por fim, sua concepção de mulher onírica, que a conforma como uma "Figura romântica e estereotipada sem os detalhes do cotidiano" (BERLINCK, 1976, p. 112)

Nascidas e criadas para servir o homem e realizar tarefas simples e corriqueiras do lar, essas mulheres viveram dominadas por esse sistema patriarcal estabelecido e construído na sociedade como regra a ser seguida. Neste sentido, esta canção representa as mulheres que não podiam nem ao menos ser escutadas e que quando eram percebidas eram retratadas cuidando de tarefas simples como limpar, lavar, cozinhar e procriar.
Em paralelo a essa representação do feminino, Chico constrói também personagens femininas que assumem o controle de sua vida, que fazem suas escolhas e rompem com a cultura patriarcal dominante, como ocorre nas canções "Mil perdões", "Madalena foi pro mar" e "Terezinha".

$\mathrm{Na}$ canção "Mil perdões", a figura feminina passa a ser ativa em suas práticas cotidianas, em que o ciúme e o sentimento de posse por parte de seu companheiro não são aceitáveis.

Verifica-se, nesta canção, que as palavras "Te perdoo" se repetem onze vezes, sendo que em todas estas repetições este homem é culpado por erros que não cometeu; pelo contrário, foram cometidos por uma mulher dona de sua vida, vaidosa, soberba, mentirosa, traidora. Essa mulher representa um papel oposto de uma sociedade patriarcal, em que o homem se utilizava de artifícios para manipular e manter a mulher a seus pés. E nesta canção o homem desempenha o papel que é dado culturalmente para a mulher, ou seja, o papel de ciumento e de submissão ao outro, como podemos notar na sua terceira estrofe: "Te perdoo/Quando anseio pelo instante de sair/E rodar exuberante/E me perder de ti/Te perdoo/Por quereres me ver/Aprendendo a mentir (te mentir, te mentir)". No desenrolar de toda a canção o homem mantem-se numa condição submissa aos desejos e atitudes dessa personagem feminina que ironiza seu comportamento. 
A mulher aqui representada sustenta uma relação sem respeito e sem pudor, em que mesmo tendo sua palavra e a liberdade de escolha, carrega um peso por não conseguir viver plenamente essa relação. A relação de ambos se apresenta disfuncional, pois a mulher vive de seu próprio modo e aventuras, porém, está presa ao homem com toda a sua instabilidade emocional e agressividade. Aliás, esta agressividade nos remete à cultura patriarcal, em que o homem garante sua dominação pelo uso da força física. Podemos perceber esse sistema na segunda estrofe: “Te perdoo/Te perdoo por ligares/Pra todos os lugares/De onde eu vim/Te perdoo/Por ergueres a mão/Por bateres em mim".

Em "Madalena foi pro mar", podemos perceber outra posição em que a mulher rompe com o ideal da maternidade que lhe é imposto, visto que a sociedade, organizada segundo os preceitos cristãos e patriarcais, atribuiu que as relações amorosas ocorram de maneira a reproduzir, e a cada vez mais, solidificar seus preceitos organizadores. Portanto, a mulher precisa produzir filhos para a manutenção desse sistema social. Além disso, espera-se da mãe um conjunto de atitudes, sentimentos, como algo aguardado por todos e aceito pela mesma. Normas em que a sociedade separa o que é dever de uma mulher e do homem, como exemplo, a criação do filho, que muitas vezes imposta como plena responsabilidade, única e exclusiva da mulher.
De acordo com Adélia Bezerra de Menezes em "Dois Guris - Ou a Maternidade ferida":

A canção de Chico
transcende o caso
individual e, pela força da
palavra poética, atinge o
universal. Mas nesse
universal cada um poderá
ver, embutida, a questão,
que é a questão de cada ser
humano; seres sujeitos ao
desgarramento, a perdas,
passíveis de sermos
afetivamente
despedaçados.

(MENEZES, 2013, p. 26)

Vista como um ser que tem que estar a serviço não só do casamento, do lar, mas também da criação dos filhos, ainda existe o estranhamento em circunstâncias em que a mulher escolhe trabalhar fora, mesmo tendo uma criança em casa. As transformações pela busca de autenticidade e liberdade nas mulheres acarretam peso, culpa e cobrança desnecessárias, incutidas no seio familiar machista, advindo de uma sociedade alienada nos preceitos patriarcal. Chico Buarque representa na canção "Madalena foi pro mar" - canção que se opõe a "Mulheres de Atenas" por apresentar a mulher ativa e dona de seu destino -, uma mulher que dedicou sua vida a cuidar dos seus filhos e que, por alguma razão, os abandonou, indo embora em alto mar. Em um dado momento de sua vida, essa mulher abandona os papéis estabelecidos na sociedade e segue noutra direção. Podemos dizer que apesar da dor do abandono dos 
filhos, Madalena foi para o mar em busca do renascimento para sua própria existência, quebrando padrões estabelecidos em uma sociedade dominada pelo patriarcalismo, em que a mulher "não pôde" viver fora da dominação masculina. Madalena, como qualquer outra mulher que gera um filho, tem direito de vida, de escolha e ela escolheu romper com o sistema que a dominou. Nesta canção, o homem corre à procura de Madalena: "Madalena foi pro mar/E eu fiquei a ver navios/Quem com ela se encontrar/Diga lá no alto mar/Que é preciso voltar já/Pra cuidar dos nossos filhos". Madalena escolheu subverter a dominação masculina dando a si mesma a chance de viver uma nova história.

Através da cantiga popular "Terezinha de Jesus", Chico compôs “Terezinha”, canção que retrata uma mulher que espera o seu amor, porém como dona de sua vida e história esta mulher tem domínio sobre suas escolhas. Adélia Bezerra diz que:

\begin{tabular}{lrr} 
Terezinha & \multicolumn{2}{r}{ torna-se } \\
"Tereza": & passou & de \\
criança a mulher. & No \\
processo do & seu \\
amadurecimento pessoal, & quando está apta & a \\
encontrar-se com & o \\
masculino, ela é mulher. \\
(MENEZES, 2001, p. \\
111).
\end{tabular}

É através de três homens diferentes que Terezinha encontra seu amor, por meio de sua escolha.
O primeiro homem que chegou a Terezinha veio contando suas vantagens e suas histórias, partiu de uma concepção a qual a conquista de uma mulher seria realizada por meio do oferecimento de presentes, em dar e oferecer coisas de valor, percebendo em sua concepção, essa mulher como interesseira.

O segundo chegou como se viesse de um bar, trouxe a aguardente, indagou o seu passado, cheirou e vasculhou como um homem rude, sem escrúpulos, a chamou de perdida, sem pudor. Nestas situações, nenhum desses dois homens alcançou o amor e reconhecimento de Terezinha, que sabia o que queria, pois Terezinha não é seduzida por essas posturas que não a enxerga como uma mulher em sua plenitude.

O terceiro não tinha nada para lhe oferecer, também não lhe julgou, simplesmente a reconheceu como uma mulher como vemos na quinta estrofe: "O terceiro me chegou/Como quem chega do nada/Ele não me trouxe nada/Também nada perguntou/Mal sei como ele se chama/Mas entendo o que ele quer!/Se deitou na minha cama/E me chama de mulher". Instalou-se em sua vida, pois sendo seu desejo, também não lhe cobrava nada. E nesta situação Chico apresenta o que há de verdadeiro em uma relação, isto é, o reconhecimento, de modo a permitir que o outro exista conforme seus direitos e seus sonhos.

O sistema sociocultural em que vivemos impõe um sentimento de culpa à 
mulher que a impede de lutar e a faz acreditar que é natural aquilo que lhe é imposto culturalmente, muitas vezes agindo contra a própria mulher e em favor do homem.

Chico Buarque de Hollanda expressa a voz dessas mulheres que em tempos difíceis, de ditaduras e repressão, em que muitos tinham a possibilidade de expressão. Como compositor, Chico se destacou por reconhecer o outro, preocupado com o miserável, com um olhar sensível aos pobres, aos marginalizados, dando visibilidade ao fraco e ao indivíduo sem posição social.

A canção foi $o$ instrumento que $o$ compositor utilizou para denunciar, de maneira sutil, a ideologia patriarcal dominante, alertando as pessoas sobre suas opressões, reconhecendo o outro e manifestando sua indignação contra o opressor.

Compreendemos que Chico Buarque não pretende que a mulher assuma a posição destinada ao homem; pelo contrário, sua reflexão instiga para que as mulheres possam assumir seu espaço, ter sua palavra própria, sua independência, seus sonhos e desejos e participe da sociedade, do lar e da história humana em condições de igualdade com o ser masculino.

Infelizmente no decorrer da história a mulher sempre foi alvo de violência simbólica. ${ }^{1}$ O homem sempre estabeleceu

\footnotetext{
1 [...] se institui por intermédio da adesão que o
} dominado não pode deixar de conceder ao dominante modelos para seu comportamento e determinou o lugar a ser ocupado por ela. Situação, por ser constante, cristalizou-se assumindo um aspecto "natural". Esta condição de submissão imposta à mulher a impediu de assumir suas escolhas e de realizar seus desejos. Mulheres submetidas à opressão sem poder escolher o que queriam, o que desejavam ou ansiavam. Sendo desqualificadas em suas palavras, sem força ou poder para dirigir sua própria história.

Segundo Pierre Bourdieu, em seu livro A dominação Masculina, a proposição utilizada para a dominação masculina sobre a mulher foi:

A diferença biológica entre
os sexos, isto é, entre o
corpo masculino e o corpo
feminino,
especificamente,
diferença anatômica entre
os órgãos sexuais, pode
assim ser vista como
justificativa natural da
diferença socialmente
construída entre os gêneros
e, principalmente, da
divisão social do trabalho.
(BOURDIEU, 2002, p. 20)

(e, portanto, à dominação) quando ele não dispõe, para pensá-la e para se pensar, ou melhor, para pensar sua relação com ele, mais que de instrumentos de conhecimento que ambos têm em comum e que, não sendo mais que a forma incorporada da relação de dominação, fazem esta relação ser vista como natural; ou, em outros termos, quando os esquemas que ele põe em ação para se ver e se avaliar, ou pra ver e avaliar os dominantes (elevado/baixo, masculino/feminino, branco/negro etc.), resultam da incorporação de classificações, assim naturalizadas, de que ser social é produto." (BOURDIEU, 2002, p.47) 
De acordo com Bourdieu, é esta diferença anatômica que confere valor social, pois é através da virilidade física que o homem prova toda a sua potência como, por exemplo, na defloração da noiva. No Falo concentram-se as fantasias de potência coletiva. Além deste símbolo de vida e de dominação, Bourdieu nos remete a uma descoberta de um escrito da Idade Média em que a vagina é apresentada como um falo invertido, ou seja, enquanto o órgão masculino é o positivo, o feminino é o negativo, é o direito e o avesso, e o princípio masculino passa a ser a medida de todas as coisas.

Assim, a cultura inconscientemente adquiria a ideia de domínio sobre a vida da mulher que se estendeu por anos, com estereótipos de uma mulher passiva, sem poder, postulada como um ser a serviço do lar, sem palavras para queixas, sem direitos, sem poder sonhar.

Construções adquiridas em um plano social, a fim de se instituir uma ordem que determina o que é próprio à mulher e ao homem, e o que é aceitável ou não, desejado ou não, sobre as mulheres a fim de encarregálas com condições diárias mesquinhas. Como argumenta Pierre Bourdieu:

Pelo fato de o mundo limitado em que elas estão confinadas, o espaço do vilarejo, a casa, a linguagem, os utensílios, guardarem os mesmos apelos à ordem silenciosa, as mulheres não podem senão tornar-se o que elas são segundo a razão mítica, confirmando assim, e antes de mais nada a seus próprios olhos, que elas estão naturalmente destinadas ao baixo, ao torto, ao pequeno, ao mesquinho, ao fútil etc. (BOURDIEU, 2002, p. 41)

Chico Buarque, com sua capacidade peculiar de expressão, consegue desmascarar, em suas canções, a condição de submissão em que as mulheres são forçosamente alojadas. Sensibilidade que o compositor tem em representar essas várias mulheres que se adequam ao sistema concebido como algo que ocorre naturalmente e outras que escolhem novas direções de rumos a seguir em suas trajetórias, tendo força e mudança de comportamento através de suas palavras, de suas escolhas.

Perceber que existem escolhas e que mulheres têm se apropriado de sua vida, para seu beneficio libertador, nos faz acreditar em mudanças, mesmo sabendo que ainda perdura em pleno século XXI a dominação masculina sobre a mulher. Verificam-se evidências que nos mostram o apego ao poder da dominação sobre o outro, em que o homem abre espaço para que possa tirar vantagens sobre a mulher. Percorrer o caminho contrário que por séculos foi alimentado pela escravidão de vários aspectos, principalmente construído socialmente referente a essa mulher, não é e nunca será tão fácil na história, mas trilhar e 
modificar os comportamentos pela luta de uma nova perspectiva de vida em relação aos sexos faz com que a expectativa e esperança por dias melhores se concretizem. O caminho é longo, mas se faz necessário percorrê-lo.

\section{Conclusão}

Chico Buarque de Hollanda por meio de suas composições musicais extremamente elaboradas, nos envolve em um universo solidário aos humildes e aos desvalidos, com especial atenção a condição de desprestígio e submissão que a mulher ocupa em nossa sociedade, bem como sua capacidade e força para romper com a cultura patriarcal dominante. Ao lançar seu olhar para o desqualificado, o compositor evidencia em suas canções a estrutura social opressora a qual somos submetidos e nos aproxima dos menos favorecidos e das representações do mundo feminino, composto por suas diversas personalidades e posturas. Chico põe em evidência a voz das mulheres, possibilitando a visibilidade destas. Suas composições revelam que no processo histórico pelo qual passamos as mulheres foram caladas por uma concepção ideológica religiosamente patriarcal, acarretando dores imensuráveis e até a sua morte. Suas canções nos convidam a refletir sobre a condição que a mulher ocupou e ainda ocupa em nossa sociedade, marcadamente machista, que nega seus direitos de igualdade.

\section{Referências Bibliográficas}

BERLINCK, Manoel Tosta. Sossega Leão! Algumas considerações sobre o samba como forma de cultura popular. Contexto, São Paulo, no 1, p. 101-114, nov. 1976.

BOURDIEU, Pierre. A dominação Masculina. Rio de Janeiro: Editora Bertrand Brasil, 2002.

CHICO BUARQUE. Disponível em: < http://www.chicobuarque.com.br/>. Acesso em: 16 de jul. de 2017.

MENESES, Adélia Bezerra de. Dois Guris Ou a Maternidade Ferida. In: FERNANDES, Rinaldo (org.) Chico Buarque: o poeta das mulheres, dos desvalidos e dos perseguidos São Paulo: LeYa, 2013, p. 19-29.

MENESES, Adélia Bezerra de. Figuras do Feminino na canção de Chico Buarque. Cotia - SP: Ateliê Editorial, 2001.

PEREIRA, Cilene Margarete. "Rita", de Chico Buarque (e outras histórias femininas de devastação). RECORTE - Revista eletrônica. Mestrado em Letras: Linguagem, Cultura e Discurso/UNINCOR. V. $14-\mathrm{N}^{\circ}{ }^{\circ} 2$ (Julho-dezembro - 2017). Disponível em: http://periodicos.unincor.br/index.php/recorte/ article/view/4271/3259. Acesso em: 09-122017. 